\title{
GREEN LIGHT PHOTOSELECTIVE VAPORIZATION OF THE PROSTATE: ONE LASER FOR DIFFERENT PROSTATE SIZES
}

\author{
GreenLight in prostate less and more than $100 \mathrm{cc}$ \\ Davide Campobasso \\ Dept. of Urology, Ospedale Civile di Guastalla and Ospedale Ercole Franchini di Montecchio \\ Emilia, Azienda USL-IRCCS di Reggio Emilia, Italy \\ Phone: +39 0522-837369 \\ Fax: +39052283736 \\ E mail:d.campobasso@virgilio.it \\ Michele Marchioni \\ Dept. of Medical, Oral and Biotechnological Sciences,"G. D'Annunzio" University of Chieti, \\ Chieti, Italy \\ Phone: +390871.357755 \\ Fax: +390871.357600 \\ E-mail: mic.marchioni@gmail.com \\ Vincenzo Altieri \\ Department of Urology, Humanitas Gavazzeni, Bergamo, Italy \\ Phone: +39035 4204300 \\ Fax: +3903542045004204500 \\ E-mail: vmaltieri@alice.it \\ Francesco Greco \\ Department of Urology, Humanitas Gavazzeni, Bergamo, Italy \\ Phone: +39035 4204300 \\ Fax: +3903542045004204500 \\ E-mail: francesco_greco@ymail.com
}


Cosimo De Nunzio

Dept of urology, "Sant'Andrea" Hospital, Sapienza University, Roma, Italy

Phone: +3906.3377 .5820$

Fax: +3906.3377 .5343$

E-mail: cosimodenunzio@virgilio.it

Paolo Destefanis

Dept. of Urology, Azienda Ospedaliera Città della Salute e della Scienza di Torino - Sede

Molinette, Torino, Italy

Phone: +39 011/633.5416

Fax: $+39011 / 633.65774204500$

E-mail: pdestefanis2@molinette.piemonte.it

Stefano Ricciardulli

Dept. of Urology, “Arcispedale Santa Maria Nuova”, Reggio Emilia, Italy

Phone: +390522 296179

Fax: +390522 2967464204500

E-mail: stefano.ricciardulli@gmail.com

Franco Bergamaschi

Dept. of Urology, “Arcispedale Santa Maria Nuova”, Reggio Emilia, Italy

Phone: +390522 296179

Fax: +390522 2967464204500

E-mail: bergamaschi.francoantoniomario@ausl.re.it

Giuseppe Fasolis

Dept. of Urology, "S. Lazzaro" Hospital, Alba, Italy

Phone: +390173 316.595

Fax: +390173 316.5964204500

E-mail: gfasolis@aslcn2.it 
Francesco Varvello

Dept. of Urology, "S. Lazzaro" Hospital, Alba, Italy

Phone: +390173 316.595

Fax: +390173316.596 4204500

E-mail: fvarvello@aslcn2.it

Salvatore Voce

Dept. of Urology, "Santa Maria delle Croci Hospital”, Ravenna, Italy

Phone: +39 0544285479

Fax: $+39 \underline{0544285327} 4204500$

E-mail: svoce@libero.it

Fabiano Palmieri

Dept. of Urology, "Santa Maria delle Croci Hospital", Ravenna, Italy

Phone: +39 $\underline{0544285479}$

Fax: $+39 \underline{0544285327} \quad 4204500$

E-mail: fabianopalmieri@libero.it

Claudio Divan

Dept. of Urology, "Rovereto Hospital”, Rovereto, Italy

Phone: $+39 \underline{0461903306}$

Fax: +390461903101

E-mail: claudio.divan@apss.tn.it

Gianni Malossini

Dept. of Urology, "Rovereto Hospital”, Rovereto, Italy

Phone: +39 $\underline{0461903306}$

Fax: +390461 903101

E-mail: gianni.malossini@apss.tn.it 
Rino Oriti

Dept. of Urology, “Ulivella e Glicini Clinic”, Florence, Italy

Phone: +39 $\underline{3421853227}$

Fax: +390941703260 4204500

E-mail: rinooriti@yahoo.it

Agostino Tuccio

Department of Urology, University of Florence, Unit of Oncologic Minimally-Invasive

Urology and Andrology, Careggi Hospital, Florence, Italy.

Phone: +39 055794111

Fax: +3905579477904204500

E-mail: agostinotuccio@yahoo.it

Lorenzo Ruggera

Dept. of Urology, Clinica urologica azienda ospedaliera - University of Padova, Padova, Italy

Phone: +390498212730

Fax: +390498218757 4204500

E-mail: lorenzoruggera@yahoo.it

Andrea Tubaro

Dept. of Urology, "Sant'Andrea" Hospital, Sapienza University, Roma, Italy

Phone: +39 06.3377.5820

Fax: +3906.3377 .5343$

E-mail: andrea.tubaro@mac.com

Giampaolo Delicato

Dept. of Urology, “S. Giovanni Evangelista” Hospital, Tivoli, Italy

Phone: +39-07743164530

Fax: +3907743164531ù

E-mail: gdelicato@libero.it 
Antonino Laganà

Dept. of Urology, "S.Giovanni Evangelista" Hospital, Tivoli, Italy

Phone: +39-07743164530

Fax: +3907743164531

E-mail: antoninolagana@gmail.com

Claudio Dadone

Dept. of Urology, "Santa Croce e Carle" Hospital, Cuneo, Italy

Phone: +39-0171.641436

Fax: +390171.641271

E-mail: cdadone@alice.it

Gaetano De Rienzo

Dept. of Emergency and Organ Transplantation, Urology and Andrology Unit II, University of Bari, Bari, Italy

Phone: +390805592893

Fax: +3908055931504204500

E-mail: gaetanoderienzo@gmail.com

Antonio Frattini

Dept. of Urology, Ospedale Civile di Guastalla ed Ospedale Ercole Franchini di Montecchio Emilia, Azienda USL-IRCCS di Reggio Emilia, Italy

Phone: +39 0522-837369

Fax: 052283736

E mail: antonio.frattini@ausl.re.it

Lugi Pucci

Dept. of Urology, AORN “Antonio Cardarelli", Naples, Italy

Phone: +390817472475

Fax: +39 0817472464

E mail: luigi.pucci@aocardarelli.it 
Maurizio Carrino

Dept. of Urology, AORN “Antonio Cardarelli”, Naples, Italy

Phone: +39 0817472475

Fax: +390817472464

E mail: cris63@libero.it

Franco Montefiore

Dept. of Urology, "San Giacomo" Hospiutal, Novi Ligure, Italy

Phone: +390143 332111

Fax: +39 0143/332709

E mail: fmontefiore@aslal.it

Stefano Germani

UOSD Urologia, Fondazione Policlinico Tor Vergata, Rome, Italy

Phone: +39 06.2090.0591

Fax: +39 06.2090.2865

E mail: s-germani@libero.it

\section{Roberto Miano}

UOSD Urologia, Dipartimento di Scienze Chirurgiche, Fondazione Policlinico Tor Vergata, Università di Roma Tor Vergata, Rome, Italy

Phone: +39 06.2090.0591

Fax: +3906.2090 .2865$

Email: mianor@virgilio.it

Luigi Schips

Dept. of Urology, ASL Abruzzo2, Chieti, Italy

Phone: +390871.357755

Fax: +390871.357600

E-mail: luigischips@hotmail.com 
Salvatore Rabito

Dept. of Urology, “Hesperia Hospital”, Modena, Italy

Phone: +39059.449170

Fax: +39059.394840

E-mail: salvorabito@hotmail.it

\section{Giovanni Ferrari}

Dept. of Urology, “Hesperia Hospital”, Modena, Italy

Phone: +39059.449170

Fax: +39059.394840

E-mail: gferrari@hesperia.it

Luca Cindolo

Dept. of Urology, "Villa Stuart" Private Hospital, Rome, Italy

Phone: +390635528500

Fax: +390635402281

E-mail: lucacindolo@virgilio.it

\section{Corresponding Author:}

Davide Campobasso

Dept. of Urology, Ospedale Civile di Guastalla ed Ospedale Ercole Franchini di Montecchio

Emilia, Azienda USL-IRCCS di Reggio Emilia, Italy

Phone: +39 0522-837369

Fax: +39052283736

Email: d.campobasso@virgilio.it 
ABSTRACT

INTRODUCTION

GreenLight laser vaporization of the prostate (PVP) is a safe and effective procedure for Benign Prostatic Hyperplasia. Long term results and advantages of PVP in patients with large and symptomatic prostate are still under evaluation.

MATERIALS AND METHODS

In a multicenter experience, patients who underwent standard or anatomical PVP were retrospectively reviewed. Patients with follow-up $>12$ months were divided into two groups based on prostate volume ( $<100 \mathrm{cc}$ vs $\geq 100 \mathrm{cc}$ ). Pre- and peri-operative data as well as post-operative results and complications were recorded after 3, 6, 12 months and then annually.

RESULTS

1031 patients were eligible, 916 of these had a prostate volume of $<100 \mathrm{cc}$ and $115 \geq 100$ cc. Median follow-up period was 25.0 months (IQR 16.5-35.0) and 16.0 months (IQR 12.0$24.0)$ in $\geq 100$ and $<100$ groups, respectively. No difference was found in terms of catheterization time, post-operative stay and post-operative acute urine retention. Patients with prostate $\geq 100$ required longer operative time ( 75 versus 55 minutes), lasing time (41.7 versus 24.9 minutes), and higher energy used but lower energy density. Patients with prostate $\geq 100$ had a higher incidence of early (50.4 versus $35.7 \%$ ) and late complications (21.7 versus $12.8 \%$ ) and early urge/incontinence symptoms (40.9 versus $29.3 \%$ ). No statistically significant differences were found for the Qmax and IPSS results between the two groups. The re-intervention rate in $\geq 100$ group was $3.5 \%$ versus $2.3 \%$ in $<100$.

\section{CONCLUSIONS}

In the midterm follow-up, Greenlight PVP guarantees the same results in different prostate volumes groups. Early and late complications are more frequent in large prostates.

GreenLight Laser in prostate less and more than $100 \mathrm{cc}$ 


\section{INTRODUCTION}

Since 1997, when the prototype of a 60 Watt continuous-wave Very High Power (VHP) ${ }^{\mathrm{TM}}$ laser system was first used, two additional Green Laser devices have been introduced, the 80W Potassium Titanyl Phosphate (KTP) and the 120W high-performance system (HPS) ${ }^{\mathrm{TM}}$ Lithium Triborate (LBO) [1].

These three laser systems differ in maximum power output and fiber design, and this evolution has been researched to allow higher and faster tissue ablation and lower fiber degradation [1]. Nowadays, Green light laser photoselective vaporisation of the prostate (PVP) is a consolidated and safe technique for Benign Prostatic Obstruction (BPO). Several papers have reported long term results with the 80W KTP and the 120W LBO, documenting lack of inferiority compared to TURP in terms of International Prostate Symptom Score (IPSS) and peak urinary flow rates, with lower transfusion requirements, shorter catheterization time and hospital length of stay in favor of PVP, while re-operation rates and operation time are in favor of TURP [1].

The introduction of the 180 W LBO crystal Green Light Xcelerated Performance System (XPS)TM (American Medical System-AMS, Minnetonka, Minnesota) with a new $532 \mathrm{~nm}$ wavelength, metal-capped and liquid cooled irrigated fiber (Moxy TM fiber) and the development of different PVP techniques (standard photovaporization- PVP, anatomical PVP and GreenLight enucleation of prostate - GreenLEP) have permitted to vaporize more tissue in a shorter time with less fibers used, aiming to reduce re-treatment rates [1-3]. The European Association of Urology (EAU) guidelines recommend Green light laser vaporisation of the prostate to men with moderate-to-severe lower urinary tract symptoms (LUTS) as an alternative to TURP with a level of evidence (LE) of 1a (evidence obtained from meta-analyses of randomized trials) for short-term results with the $80 \mathrm{~W}$ KTP laser and for mid-term results with the 120W, and of LE-1b (evidence obtained from at least one randomized trial) with the 180W LBO laser [4]. Conversely, for patients affected by large and symptomatic prostates, long-term functional results and re-operation rates after PVP performed with the 180 W LBO laser are mainly based on retrospective data [1, 5-10]. 
Based on these considerations, we decided to analyze a large multicenter cohort of 1031 patients in order to evaluate complication rates and functional outcomes in patients with BPO treated by $180 \mathrm{~W}$ LBO laser according to prostate volume.

\section{MATERIALS AND METHODS}

We retrospectively reviewed cases undergoing standard or anatomical PVP in a multiinstitutional prospectively collected database between September 2011 and October 2017 using the 180-W XPS GL system for BPO. The study involved several surgeons with consolidated experience in GreenLight. Informed consent was obtained from all individual participants included in the study. This study and all related procedures have been performed in accordance with the Declaration of Helsinki. Patients with history of prostate cancer, neurogenic bladder disease, previous prostate surgery as well as those who underwent GreenLEP or contemporary urethrotomy, treatment of bladder stones, and with incidental bladder tumors were excluded. Surgical procedures were performed according to surgeon's preferences, as previously described [1,3]. All the procedures start with visualization of the striated sphincter, the ureteral orifices and the exclusion of bladder tumors. In standard PVP, after the creation of a working space at 5 and 7 o'clock, the prostate is vaporized in a centrifuge way from the prostatic urethra towards the prostatic capsule (inside out). Conversely, in anatomical PVP after the localization of the capsule at the apex of the prostate, the surgeon performs a bilateral incision lateral to veru montanum and the tip of the resectoscope is used to find the anatomical plane between the prostatic capsule and the adenoma. The dissection plane is followed towards the bladder neck at $6 o^{\prime}$ clock and the dissection is accompanied by vaporization of the enucleated tissue, which is performed by firing the laser in direction of prostatic urethra (outside in). In both techniques, all the tissues were vaporized and morcellation was not necessary [3]. All procedures were performed under general or spinal anesthesia. Antibiotic prophylaxis was administered to all patients according to local practice guidelines.

Examined pre-and post-operative factors and intra- and peri-operative data include: age, American Society of Anesthesiology score (ASA), prostate volume evaluated with transrectal ultrasound (TRUS), use of antiplatelet and anticoagulant medications, LUTS therapy and history of catheterization or retention, PSA level, IPSS, maximum urinary flow (Qmax), 
operative time, lasing time, energy used, catheterization time, hospital stay and retreatment rate. Energy density was coded as energy used divided the prostate volume. All the patients were recalled and underwent an outpatient clinic evaluation at least after 3,6 , and 12 months and then annually. Follow-up was calculated as time from surgery to last visit. During follow-up visit, symptoms score (IPSS), maximum urinary flow (Qmax), and PSA level were recorded. Patient Global Impression of Improvement (PGI-I) was evaluated with PGI-I scale [11]. Complications were collected as early (within 30 post-operative days) or late (after 90 days) and classified according to Clavien-Dindo classification [12-13]. We have considered post-operative frequency and urgency as complications when they prompted additional medical examination or bothered patients. Haematuria requiring application of bladder catheter and irrigation or re-intervention or medical examination was also reported. Urinary incontinence was defined as reported incontinence of any degree and type (stress or urge incontinence) if bothersome and impairing patient quality of life.

Statistical methods.

Quantitative variables were summarized as median and interquartile range (IQR). Qualitative data were summarized as frequency and percentage. After stratification according to prostate volume ( $<100 \mathrm{cc}$ vs $\geq 100 \mathrm{cc}$ ) the Chi-square and the Mann-Whitney $\mathrm{U}$ tests tested the statistical significance in proportions and median differences. We relied on a non-parametric model for repeated measurements [14] to test the effect of prostate volume and time on PSA, Qmax and IPSS. Moreover, we tested the interaction between pre-operative prostate volume and time. Boxplots graphically depicted the distribution of PSA, Qmax and IPSS values at each time points (baseline, 6 and 12 months). Furthermore, univariable and multivariable logistic regression models tested the effect of prostate size on acute urinary retention, early and late complications rates. All the multivariate logistic regression models were adjusted for age, baseline PSA, BPO/LUTS therapy, antiplatelet/anticoagulant therapy, surgery type and history of catheter indwelling prior surgery. All tests were two-sided and the level of statistical significance was set at $p<0.05$. Analyses were performed using the R software environment for statistical computing and graphics (version 3.5.1; http://www.r-project.org/). 


\section{RESULTS}

A total of 1031 patients were eligible for the study analysis. 916 of these had a prostate volume $<100 \mathrm{cc}$ and 115 patients had a prostate volume $\geq 100 \mathrm{cc}$. The median prostate volume in <100 group was 55.0 cc (43.0-70.0) versus 112.0 cc (100.0-130.0) in $\geq 100$ group $(p<0.001)$. Patients with large prostate volume had more frequently a history of indwelling catheter $(27 \%$ versus $15 \%, p<0.001)$. Patients with prostate $\geq 100 \mathrm{cc}$ required longer operative times ( 75 versus 55 minutes, $p<0.001$ ), longer lasing times (41.7 versus 24.9 minutes, $p<0.001$ ), and higher energy used (390 versus $205 \mathrm{~kJ}, \mathrm{p}<0.001$ ) but lower energy density ( 3.3 versus $4.1 \mathrm{~kJ} / \mathrm{mL}, \mathrm{p}<0.001)$. Age, catheterization time and postoperative hospital stay were similar between the two groups (Table 1). According to Clavien-Dindo classification, the most common early complications were Grade $\mathrm{I}$ in both groups $(93.1 \%$ in $\geq 100 \mathrm{cc}$ and $87.8 \%$ in $<100 \mathrm{cc})$ and similar rates between groups were recorded (Table 2). The most frequent early complication was burning urination (13.2\%), while the most frequent late complication was storage symptoms with de novo urgency (Table 3). Patients in $\geq 100$ group had a higher risk of developing early (OR: 1.8, 95\% Cl: 1.2-2.9, p=0.009) and late complications (OR: 2.2, 95\% Cl: 1.3-3.9, $\mathrm{p}=0.004)$ (Table 4).

When analyzing functional results after surgery, no statistically significant differences were found for the Qmax and IPSS between the two groups (Table 5). All three parameters (PSA, Qmax and IPSS) improved over time (Fig 1-2-3). However, despite PSA was higher in patients with large prostate, the magnitude of decrease overtime was similar in the two groups ( $p$-value for interaction $=0.089$ ). Conversely, even if Qmax and IPSS improved over time in both groups, the Qmax increase and IPSS decrease were larger in patients with large prostates ( $p$-values for interaction $=0.022$ and 0.013 , respectively).

\section{DISCUSSION}

In general, patients with prostate volumes higher than $100 \mathrm{cc}$ undergo either simple prostatectomy (open-laparoscopic or robotic) or endoscopic enucleation procedures [4]. Simple prostatectomy is the most invasive procedure to treat BPO but it has longer functional results and it does not require dedicated instruments. Management of large prostate volumes with laser offers the major advantages of this technology (shorter catheterization and hospitalization time, fewer blood transfusion rates) [4, 7]. However, 
the approach to large prostate volumes requires experience and relevant endoscopic skills. The long learning curve of the enucleation technique and the requirement of further materials for morcellation are some of the arguments to explain the slow dissemination of this procedure in urological practice. In contrast with other laser techniques (Holmium and Thulium), the Green Light Laser allows to adapt the surgical strategy (pure enucleation versus standard or anatomical vaporization) during a single procedure without modifying the functional outcomes and the complication rates $[3,15,16]$. In this study no difference were made between patients underwent standard PVP (sPVP) or anatomical PVP (aPVP) based on our previous multicentre experience in which we did not find any difference in terms of functional results and complication rates between the two techniques [15]. In the last years several retrospective studies evaluated the safety and outcomes of Green Laser in large prostate volumes [7, 17-26]. The commonest criticisms against the use of XPS in this clinical scenario are the lack of long-term follow-up, the retrospective nature of the available literature data and the reportedly higher re-treatment rates compared to Holmium laser enucleation of the prostate (HoLEP). Our series, with a mean follow-up of 25.0 months (IQR 16.5-35.0) for prostate with a volume $\geq 100 \mathrm{cc}$ is one of the longest so far reported in the literature. The re-intervention rate in the $\geq 100$ group was $3.5 \%$ versus $2.3 \%$ in prostate less than $100 \mathrm{cc}$. These data are slightly better than those reported by the Goliath study with a 24 months re-treatment rate of 9\% [27] and worse than those reported by Ajib et al [10] with a re-treatment rate of $1.1 \%$ in a series of 370 patients with a mean follow-up of 59.4 months and a mean prostate volume of 48.6 and $78.8 \mathrm{cc}$, respectively. If we consider only large prostate series, re-treatment rates range from the no re-treatment at 12 months reported by Altay [18], 1.2\% at 24 months by Hueber [19], $2.9 \%$ by Stone [20], up to $13.2 \%$ by Meskawi [22] and $6 \%$ for $200 \mathrm{cc}$ prostate and $9 \%$ for 100-200 cc (mean follow-up: 15.9 months) of the same reviewed multi-institutional series [24]. Only five studies compared the results of photoselective vaporization in large prostate cases: $<80$ vs $\geq 80$ cc [19], $\geq 200$ cc vs $100-200$ cc [24], PVP versus en bloc enucleation (GreenLEP) [21], sPVP vs aPVP [25] and simple prostatectomy versus PVP [26]. Despite the different results of re-treatment rates reported in these papers, all the authors (including us) agree with the greater operative and lasing time in large prostate undergoing PVP. Similarly, there are no differences in hospital stay and midterm functional 
results. Valdivieso [24] and Hueber [19] reported a higher conversion rate to TURP. Hueber [19] also reported a longer catheterization time in prostate larger than $80 \mathrm{ml}$, conversely Misrai [23] described, for large prostate, shorter catheterization time in PVP than in GreenLEP. Interestingly, Lanchon et al reported a higher rate of re-catheterization and rehospitalization after PVP compared to open simple prostatectomy. Our results highlight the higher risk to develop early and late complications of large prostate as well as early urge incontinence symptoms, similarly to Hibon et al [25]. In our series early and late storage symptoms/De novo urgency are $22.2 \%$ and $4.8 \%$ respectively. These data are in line with the results reported in the literature. The groups of Zorn and Misrai [10] reported irritative voiding symptoms of $18.8 \%$ at three months. This incidence dropped to $8.46 \%$ at one year. In a series of large prostate treated with GreenLaser irritative symptoms are described in $10.2 \%$ patients [22]. In agreement with previous series, we confirm no differences in catheterization time. In our series, the PSA drop, used as a proxy of removed tissue, is $51.1 \%$ and $64.5 \%$ in $\geq 100$ versus $44.4 \%$ and $51.8 \%$ in $<100$ group at 6 and 12 months, respectively. The decrease is statistically significant. This reduction is greater in $\geq 100(p=0.013)$ and continues over time $(p<0.001)$, but the interaction between prostate volume and follow-up time is not statistically significant $(p=0.089)$, implying that despite the larger amount of tissue removed the magnitude of change is not different between large and small prostate volume: the effectiveness is similar in the two groups. In the literature the cut-off of $50 \%$ of PSA reduction is established as the surgical goal to reduce re-treatment risk [28]. Probably the PSA drop recorded in our centers (64.5\%) at 12 months might explain our low re-treatment rate (3.5\%). Qmax and IPSS improve after surgery, with no difference between the two groups ( $p=0,097$ and $p=0.207$ respectively), and with improvement over time ( $p<0.001)$. At 12 months Qmax increased by $118.3 \%$ in $<100$ and $162,3 \%$ in $\geq 100$. This result might correlate with the major volume of tissue vaporized in large prostate, which is linked to an efficient vaporization and an improvement of urodynamic performances.

Even if Valdivieso et al. reported a $5 \mathrm{KJ} / \mathrm{cc}$ energy density to achieve $80 \%$ of PSA reduction at 24 months in prostate $<100 \mathrm{cc}$ (this target in larger prostate might be time- and fiberconsuming), a 3-4kJ/cc cut-off has been proposed as the minimum threshold to obtain adequate adenoma vaporization [28]. In the $\geq 100$ group the mean energy density was 3,3 
$\mathrm{KJ} / \mathrm{cc}$ (IQR 2.3-4.2), less than in $<100$ group, where it was $4,1 \mathrm{KJ} / \mathrm{cc}(\operatorname{IQR} 2.7-5.4)(\mathrm{p}<0.001)$. The lower energy density in the $\geq 100$ group might be explained by the greatest use of aPVP (63\%), as already described [15].

There are some limitations in this study: the retrospective design, the involvement of several surgeons with different level of expertise, the heterogeneity between centers to report and manage pre- and post-operative events, and the lack of number of fibers used per procedure. Another confounding factor might be the multi-center nature of this study involving different surgeons with variable surgical experience. Although all these aspects might represent limitations, from our perspective they strengthen the general perception that laser is a safe and reliable procedure which can be adopted also by young surgeons [29-30].

\section{CONCLUSIONS}

In the midterm follow-up, Greenlight PVP using the XPS-180W is safe and effective in treating patients with prostate volumes $\geq 100 \mathrm{cc}$ compared to prostate volumes $<100 \mathrm{cc}$. Even if early and late complications are more frequent in large prostate, the improvement over time in terms of Qmax and IPSS are greater than in small prostate. This study confirms the flexibility and reliability of Greenlight Laser technique. Nevertheless a longer follow up period is necessary to better clarify the re-treatment rate and effectiveness of Greenlight in large prostates.

\section{ACKNOWLEDGMENTS}

None.

\section{DISCLOSURES}

Conflict of interest: PD, LR, CD, GF and LC do surgical tutorship for AMS and received honoraria for their tutorship. 


\section{REFERENCES}

1- Brassetti A, De Nunzio C, Delongchamps NB, Fiori C, Porpiglia F, Tubaro A. Green light vaporization of the prostate: is it an adult technique? Minerva Urol Nefrol. 2017; 69(2):109-118.

2- Gomez Sancha F, Rivera VC, Georgiev G, Botsevski A, Kotsev J, Herrmann T. Common trend: move to enucleation-Is there a case for GreenLight enucleation? Development and description of the technique. World J Urol 2015; 33(4):539-47.

3- Cindolo L, Ruggera L, Destefanis P, Dadone C, Ferrari G. Vaporize, anatomically vaporize or enucleate the prostate? The flexible use of the GreenLight laser. Int Urol Nephrol 2017;49(3):405-411.

4- Gravas S, Cornu JN, Drake MJ et al. EAU Guidelines on Management of Non-Neurogenic Male Lower Urinary Tract Symptoms (LUTS), incl. Benign Prostatic Obstruction (BPO). Edn. presented at the EAU Annual Congress Copenhagen 2018. ISBN 978-94-92671-01-1. EAU Guidelines Office, Arnhem, The Netherlands 2018

5- Castellan P, Castellucci R, Schips L, Cindolo L. Safety, efficacy and reliability of 180-W GreenLight laser technology for prostate vaporization: review of the literature. World J Urol 2015; 33(5):599-607.

6- Brunken C, Seitz C, Woo HH. A systematic review of experience of 180-W XPS GreenLight laser vaporisation of the prostate in 1640 men. BJU Int 2015;116(4):531-7. 7- Stone BV, Chughtai B, Kaplan SA, Te AE, Lee RK. GreenLight laser for prostates over $100 \mathrm{ml}$ : what is the evidence? Curr Opin Urol 2016; 26(1):28-34.

8- Mordasini L, Moschini M, Mattei A, Iselin C. GreenLight Laser for benign prostatic hyperplasia. Curr Opin Urol 2018; 28(3):322-328.

9- Calves J, Thoulouzan M, Perrouin-Verbe MA, Joulin V, Valeri A, Fournier G. Long-term Patient-reported Clinical Outcomes and Reoperation Rate after Photovaporization with the XPS-180W GreenLight Laser. Eur Urol Focus 2017 Nov 1. pii: S2405-4569(17)30243-2. doi: 10.1016/j.euf.2017.10.006. [Epub ahead of print]. 
10- Ajib K, Mansour M, Zanaty M, Alnazari M, Hueber PA, Meskawi M, Valdivieso R, Tholomier C, Pradere B, Misrai V, Elterman D, Zorn KC. Photoselective vaporization of the prostate with the 180-W XPS-Greenlight laser: Five-year experience of safety, efficiency, and functional outcomes. Can Urol Assoc J 2018; 12(7):E318-E324.

11- Hossack T, Woo H. Validation of a patient reported outcome questionnaire for assessing success of endoscopic prostatectomy. Prostate Int 2014; 2:182-187.

12- De Nunzio C, Lombardo R, Autorino R, et al. Contemporary monopolar and bipolar transurethral resection of the prostate: prospective assessment of complications using the Clavien

system. Int Urol Nephrol 2013; 45:951-959.

13- Mamoulakis C, Efthimiou I, Kazoulis S, et al. The modified Clavien classification system: a standardized platform for reporting complications in transurethral resection of the prostate. World J Urol 2011; 29:205-210.

14- Noguchi K, Gel YR, Brunner E, et al. nparLD: An R Software Package for the Nonparametric Analysis of Longitudinal Data in Factorial Experiments. Journal of Statistical Software 2012; 50. Available at: http://www.jstatsoft.org/v50/i12/, accessed February 18, 2019.

15- Cindolo L, De Nunzio C, Greco F, et al. Standard vs. anatomical 180-W GreenLight laser photoselective vaporization of the prostate: a propensity score analysis. World J Urol 2018; 36(1):91-97.

16- Ghahhari J, D'Orta C, Rizzoli A, et al. Monocenter Experience with 532 Nm-Laser Photoselective-Vaporization of the Prostate by GreenLight XPS ${ }^{\mathrm{TM}}$ Laser: Is It Really an Endourological Joker Card? Surg Technol Int 2018; 32:164-172.

17- Emara AM, Barber NJ. The continuous evolution of the Greenlight laser; the XPS generator and the MoXy laser fiber, expanding the indications for photoselective vaporization of the prostate. J Endourol 2014;28(1):73-8.

18- Altay B, Erkurt B, Kiremit MC, Guzelburc V, Boz MY, Albayrak S. 180- W XPS GreenLight laser vaporization for benign prostate hyperplasia: 12-month safety and efficacy results for glands larger than $80 \mathrm{~mL}$. Lasers Med Sci. 2015 Jan;30(1):317-23. 
19- Hueber PA, Bienz MN, Valdivieso R, et al. Photoselective Vaporization of the Prostate for Benign Prostatic Hyperplasia Using the 180 Watt System: Multicenter Study of the Impact of Prostate Size on Safety and Outcomes. J Urol. 2015 Aug;194(2):462-9. 20- Stone BV, Chughtai B, Forde JC, Tam AW, Lewicki P, Te AE. Safety and efficacy of GreenLight XPS laser vapoenucleation in prostates measuring over $150 \mathrm{~mL}$. J Endourol 2016; 30: 906-12.

21- Misrai V, Kerever S, Phe V, Zorn KC, Peyronnet B, Rouprêt M. Direct Comparison of GreenLight Laser XPS Photoselective Prostate Vaporization and GreenLight Laser En Bloc Enucleation of the Prostate in Enlarged Glands Greater than $80 \mathrm{ml}$ : a Study of 120 Patients. J Urol 2016;195:1027-32.

22- Meskawi M, Hueber PA, Valdivieso R et al. Multicenter international experience of 532 $\mathrm{nm}$-laser photo-vaporization with Greenlight XPS in men with large prostates (prostate volume > 100 cc). World J Urol. 2017;35(10):1603-1609.

23- Misraï V, Pasquie M, Bordier B, et al. Comparison between open simple prostatectomy and green laser enucleation of the prostate for treating large benign prostatic hyperplasia: a single-centre experience. World J Urol. 2018;36(5):793-799.

24- Valdivieso R, Hueber PA, Meskawi M et al. Multicentre international experience of 532-nm laser photoselective vaporization with GreenLight XPS in men with very large prostates. BJU Int. 2018;122(5):873-878.

25- Hibon G, Léonard G, Franceschi A, Misrai V, Bruyère F. A bicentric comparative and prospective study between classic photovaporization and anatomical GreenLight laser vaporization for large-volume prostatic adenomas. Prog Urol 2017; 27(8-9):482-488. 26- Lanchon C, Fiard G, Long JA et al. Open prostatectomy versus 180-W XPS GreenLight laser vaporization: Long-term functional outcome for prostatic adenomas $>80 \mathrm{~g}$. Prog Urol 2018; 28(3):180-187

27- Thomas JA, Tubaro A, Barber N, et al. A Multicenter Randomized Noninferiority Trial Comparing GreenLight-XPS Laser Vaporization of the Prostate and Transurethral Resection of the Prostate for the Treatment of Benign Prostatic Obstruction: Two-yr Outcomes of the GOLIATH Study. Eur Urol 2016;69:94-102. 
28- Valdivieso R, Meyer CP, Hueber PA et al. Assessment of energy density usage during $180 \mathrm{~W}$ lithium triborate laser photoselective vaporization of the prostate for benign prostatic hyperplasia. Is there an optimum amount of kilo-Joules per gram of prostate? BJU Int 2016; 118:633-640.

29- Castellan P, Marchioni M, Rizzoli A, et al. The Surgical Experience Influences the Safety and Efficacy of Photovaporization of Prostate with 180-W XPS GreenLight Laser: Comparison Between Novices vs Expert Surgeons Learning Curves. J Endourol 2018;32(11):1071-1077.

30- Marchioni M, Schips L, Greco F, et al. Perioperative major acute cardiovascular events after 180-W GreenLight laser photoselective vaporization of the prostate. Int Urol Nephrol. 2018;50(11):1955-1962. 


\section{Figure Legends}

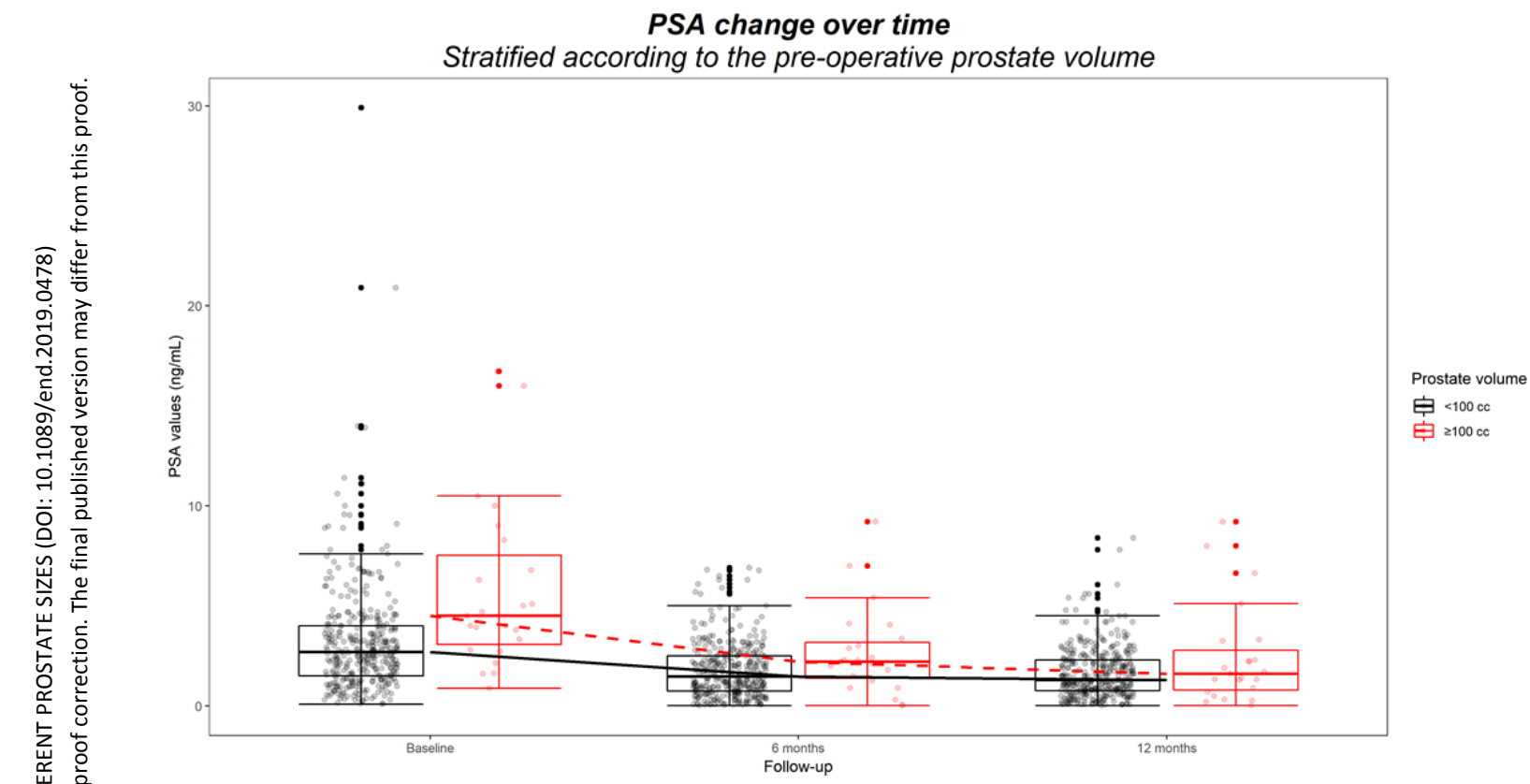

Fig. 1 - Box-whiskers graphs of baseline, 6 month and 12 months of PSA in large and small prostate groups. Box-whiskers plots show the 25th and 75th percentile range (box) with 95\% confidence intervals (whiskers) and median values (transverse lines in the box). 


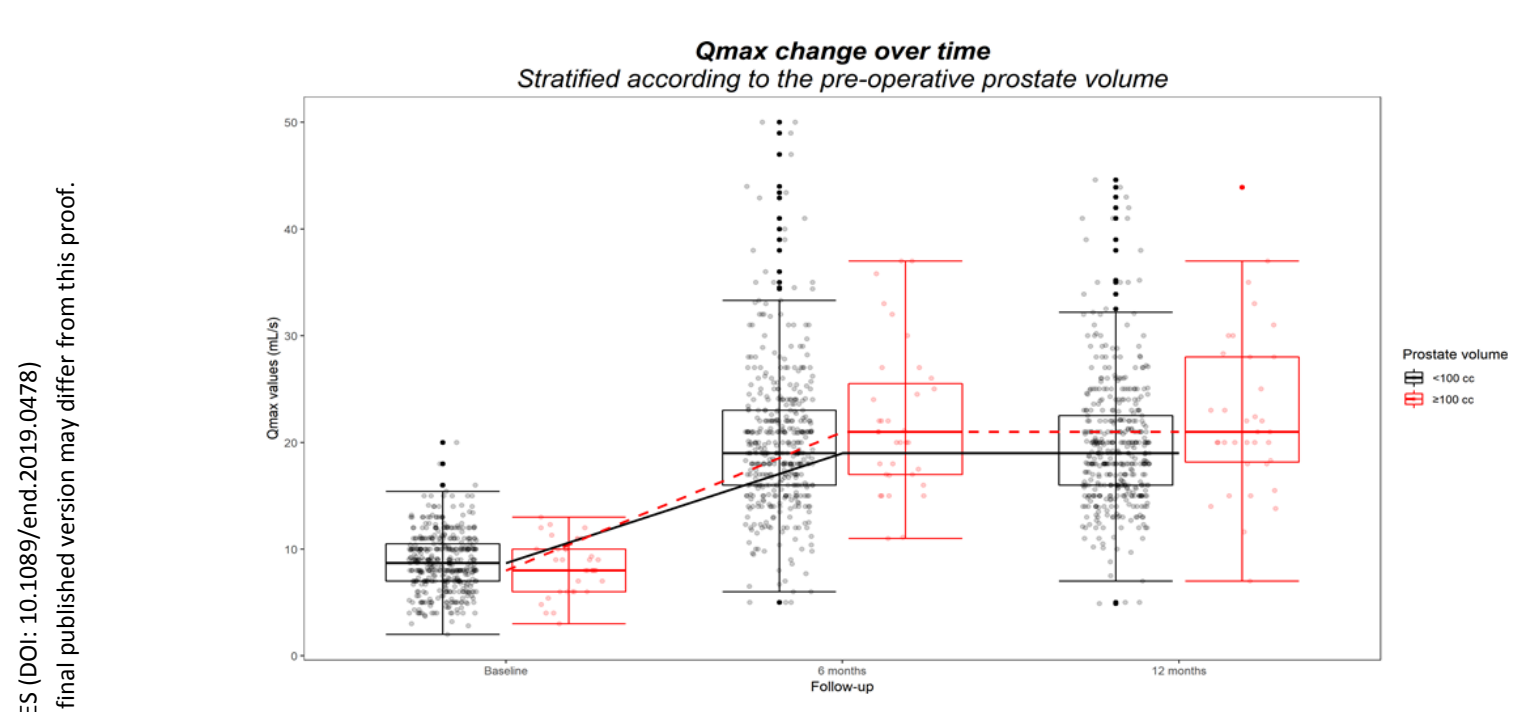

Fig. 2 - Box-whiskers graphs of baseline, 6 month and 12 months of Qmax in large and small prostate groups. Box-whiskers plots show the 25th and 75th percentile range (box) with 95\% confidence intervals (whiskers) and median values (transverse lines in the box). 
Page 22 of 30

22

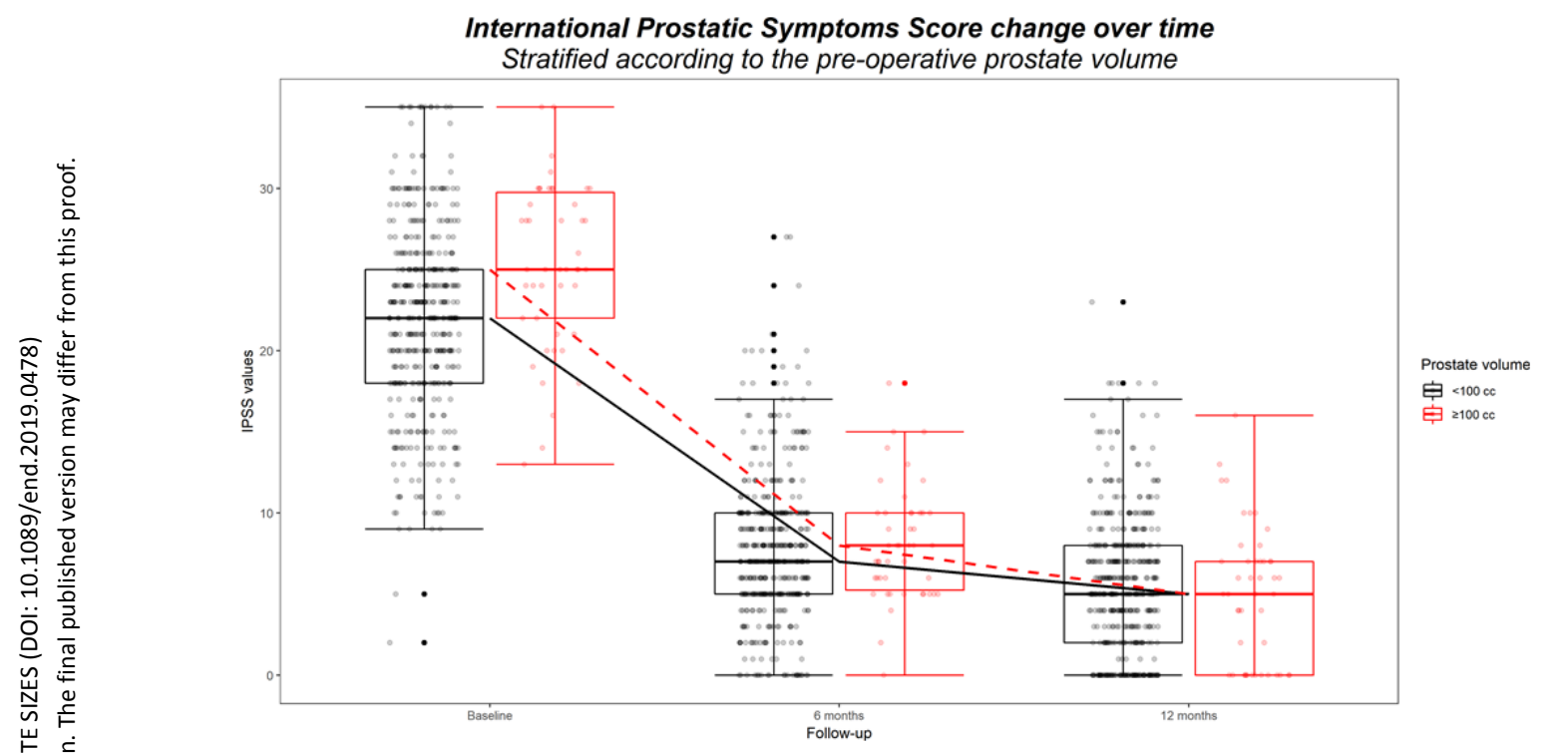

Fig. 3 - Box-whiskers graphs of baseline, 6 month and 12 months of IPSS in large and small prostate groups. Box-whiskers plots show the 25th and 75th percentile range (box) with 95\% confidence intervals (whiskers) and median values (transverse lines in the box). 
Table 1 - Patients's pre-operative and intra-operative characteristics stratified according to prostate volume.

\begin{tabular}{|c|c|c|c|c|}
\hline Variable & $\begin{array}{l}\text { Overall } \\
(n=1031)\end{array}$ & $\begin{array}{c}\text { Prostate } \\
\text { volume }<100 c c \\
(n=916)\end{array}$ & $\begin{array}{l}\text { Prostate } \\
\text { volume } \\
\geq 100 c c \\
(n=115)\end{array}$ & $p$-value \\
\hline Age (years) & $\begin{array}{c}69.0(64.0- \\
76.0)\end{array}$ & $69.0(63.0-76.0)$ & $\begin{array}{c}69.0(65.0- \\
76.0)\end{array}$ & $0.259^{b}$ \\
\hline Prostate volume (TRUS) (mL) & $\begin{array}{c}60.0(45.0- \\
75.0)\end{array}$ & $55.0(43.0-70.0)$ & $\begin{array}{c}112.0(100.0- \\
130.0)\end{array}$ & $<0.001^{b}$ \\
\hline BPH/LUTS therapy & & & & $0.029^{a}$ \\
\hline None & $164(15.9)$ & $140(15.3)$ & $24(20.9)$ & \\
\hline Alpha-blockers & $460(44.6)$ & 405 (44.2) & $55(47.8)$ & \\
\hline 5-ARI & $56(5.4)$ & $50(5.5)$ & $6(5.2)$ & \\
\hline Combination & $285(27.7)$ & $255(27.8)$ & $30(26.1)$ & \\
\hline Unknown & $66(6.4)$ & $66(7.2)$ & $0(0)$ & \\
\hline $\begin{array}{l}\text { Antiplatelet/anticoagulant } \\
\text { therapy }\end{array}$ & & & & $0.079^{a}$ \\
\hline None & $578(56.1)$ & $510(55.7)$ & $68(59.1)$ & \\
\hline Antiplatelet & $314(30.5)$ & $286(31.2)$ & $28(24.3)$ & \\
\hline Anticoagulant & $91(8.8)$ & $75(8.2)$ & $16(13.9)$ & \\
\hline Unknown & $48(4.7)$ & 45 (4.9) & $3(2.6)$ & \\
\hline $\begin{array}{l}\text { Indwelling catheter history } \\
\text { (unknown=81) }\end{array}$ & $168(16.3)$ & $137(15)$ & $31(27)$ & $<0.001^{a}$ \\
\hline ASA score & & & & $0.004^{a}$ \\
\hline $1-2$ & 473 (45.9) & $431(47.1)$ & $42(36.5)$ & \\
\hline $3-4$ & $232(22.5)$ & $211(23)$ & $21(18.3)$ & \\
\hline Unknown & $326(31.6)$ & 274 (29.9) & $52(45.2)$ & \\
\hline Surgical technique & & & & $0.079^{a}$ \\
\hline Anatomic PVP & $481(46.7)$ & $418(45.6)$ & $63(54.8)$ & \\
\hline
\end{tabular}


24

\begin{tabular}{|c|c|c|c|c|c|}
\hline \multirow{7}{*}{ 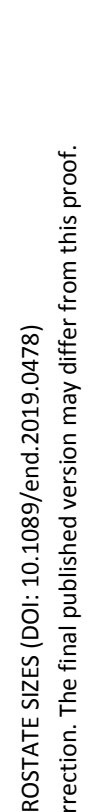 } & Standard PVP & $550(53.3)$ & $498(54.4)$ & $52(45.2)$ & \\
\hline & Operative time ( $\mathrm{min}$ ) & $\begin{array}{c}60.0(40.0- \\
75.0)\end{array}$ & $55.0(40.0-70.0)$ & $\begin{array}{c}75.0(60.0- \\
94.8)\end{array}$ & $<0.001^{b}$ \\
\hline & Lasing time (min) & $\begin{array}{c}26.0(19.0- \\
36.0)\end{array}$ & 24.9 (18.0-33.9) & $\begin{array}{c}41.7 \text { (34.0- } \\
52.0)\end{array}$ & $<0.001^{b}$ \\
\hline & Energy used (kJ) & $\begin{array}{c}221.0(145.0- \\
334.0)\end{array}$ & $\begin{array}{c}205.0(137.4- \\
302.0)\end{array}$ & $\begin{array}{c}390.0(308.5- \\
501.0)\end{array}$ & $<0.001^{b}$ \\
\hline & $\begin{array}{l}\text { Energy used }(\mathrm{kJ}) / \text { prostate } \\
\text { volume }(\mathrm{mL})\end{array}$ & $3.9(2.7-5.2)$ & $4.1(2.7-5.4)$ & $3.3(2.3-4.2)$ & $<0.001^{b}$ \\
\hline & Catheterization time (days) & $1(1-2)$ & $1(1-2)$ & $1(1-2)$ & $0.769^{b}$ \\
\hline & Post-operative stay (days) & $2(1-2)$ & $2(1-2)$ & $2(1-2.2)$ & $0.126^{b}$ \\
\hline
\end{tabular}

${ }^{a}$ Chi-squared test, ${ }^{b}$ Mann-Whitney $U$ test prostate volume $\leq 100$ vs. $\geq 100 \mathrm{cc}$. Table values are $n(\%)$ or median (IQR). PVP: photoselective vaporization of the prostate, TRUS: transrectal ultrasonography, PSA: prostate-specific antigen, IPSS: International Prostate Symptoms Score, 5-ARI: 5-alpha redeuctase inhibitors. 
Table $\mathbf{2} \neg$ Main outcomes after photoselective vaporization of the prostate stratified according to prostate volume.

\begin{tabular}{|c|c|c|c|c|}
\hline Variable & $\begin{array}{l}\text { Overall } \\
(n=1031)\end{array}$ & $\begin{array}{l}\text { Prostate volume } \\
\qquad 100 c c \\
(n=916)\end{array}$ & $\begin{array}{c}\text { Prostate } \\
\text { volume } \geq 100 c c \\
(n=115)\end{array}$ & $p$-value \\
\hline $\begin{array}{l}\text { Follow-up duration } \\
\text { (Months) }\end{array}$ & $\begin{array}{c}17.0(12.0- \\
25.3)\end{array}$ & $16.0(12.0-24.0)$ & $\begin{array}{c}25.0(16.5- \\
35.0)\end{array}$ & $<0.001^{b}$ \\
\hline Acute urine retention & $84(8.1)$ & $78(8.5)$ & $6(5.2)$ & $0.299^{a}$ \\
\hline Overall early & & & & $0.003^{a}$ \\
\hline complications & $385(37.3)$ & $327(35.7)$ & $58(50.4)$ & \\
\hline Early urge/incontinence & $315(30.6)$ & & & $0.015^{a}$ \\
\hline symptoms & & $268(29.3)$ & $47(40.9)$ & \\
\hline $\begin{array}{l}\text { Clavien-Dindo } \\
\text { classification of early } \\
\text { complication* }\end{array}$ & & & & $0.065^{a}$ \\
\hline I & $341(88.6)$ & $287(87.8)$ & $54(93.1)$ & \\
\hline II & $31(8.1)$ & $30(9.2)$ & $1(1.7)$ & \\
\hline IIla & $3(0.8)$ & $3(0.9)$ & $0(0)$ & \\
\hline IIIb & $3(0.8)$ & $3(0.9)$ & $0(0)$ & \\
\hline IVa & $7(1.8)$ & $4(1.2)$ & $3(5.2)$ & \\
\hline Overall late complications & $142(13.8)$ & $117(12.8)$ & $25(21.7)$ & $0.001^{a}$ \\
\hline $\begin{array}{l}\text { Patient global impression } \\
\text { of improvement }\end{array}$ & & & & $0.012^{a}$ \\
\hline 1 & $510(49.5)$ & $447(48.8)$ & $63(54.8)$ & \\
\hline 2 & $302(29.3)$ & $272(29.7)$ & $30(26.1)$ & \\
\hline 3 & $70(6.8)$ & $68(7.4)$ & $2(1.7)$ & \\
\hline 4 & $24(2.3)$ & $22(2.4)$ & $2(1.7)$ & \\
\hline 5 & $8(0.8)$ & $8(0.9)$ & $0(0)$ & \\
\hline 6 & $4(0.4)$ & $3(0.3)$ & $1(0.9)$ & \\
\hline 7 & $1(0.1)$ & $0(0)$ & $1(0.9)$ & \\
\hline
\end{tabular}


Page 26 of 30

* Percentage refers only to the group of patients who experienced early complications. a Chi-squared test, b Mann-Whitney U test prostate volume $<100 \mathrm{vs.} \geq 100 \mathrm{cc}$. Table values

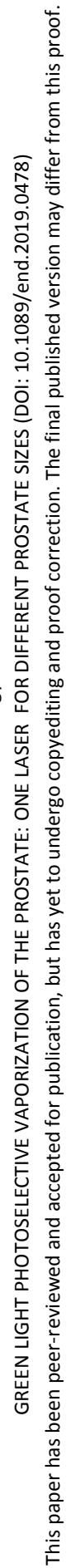
are $\mathrm{n}(\%)$ or median (IQR). 
Table 3 - Early and late complications stratified according to prostate volume.

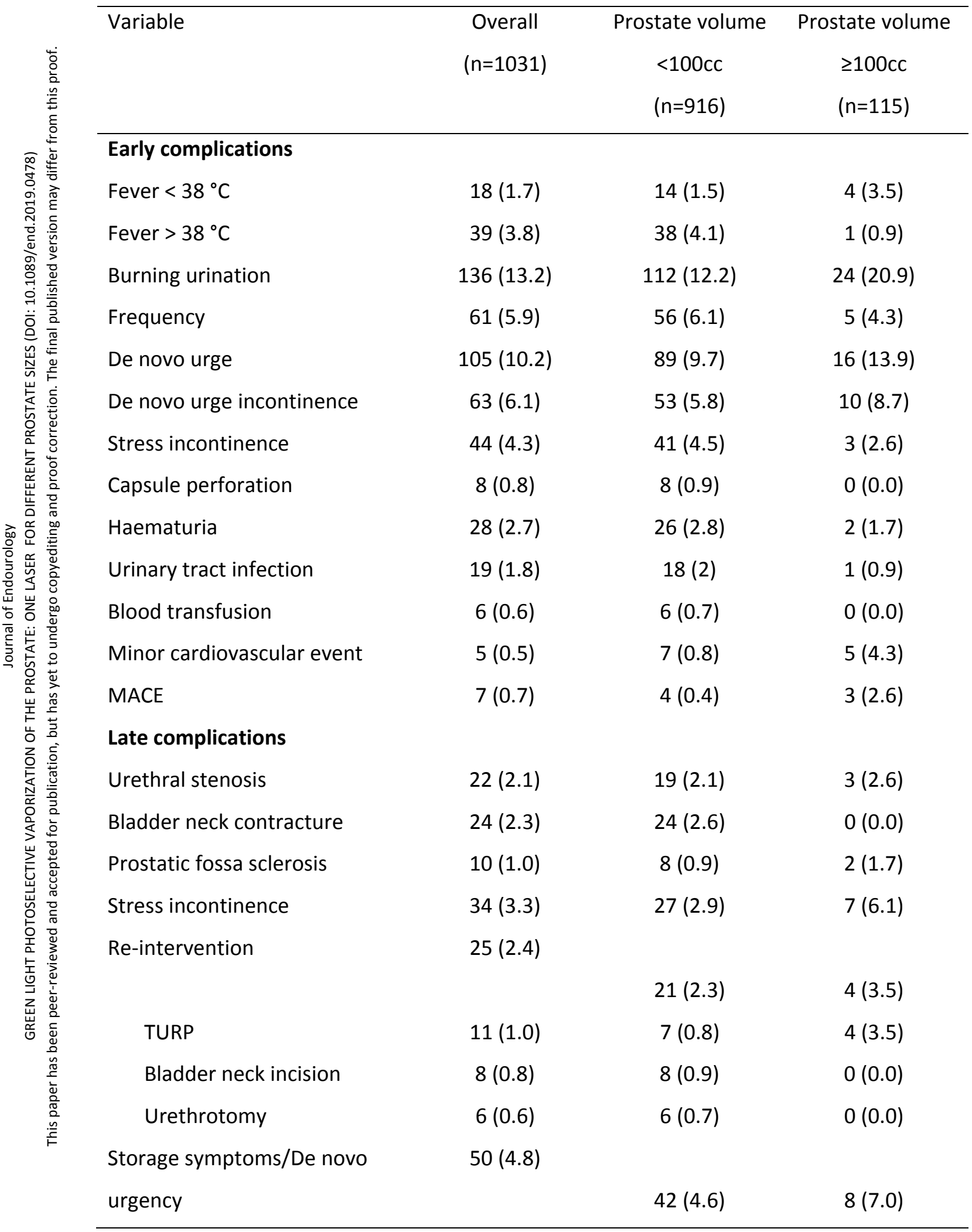


Table 4 - Multivariable logistic regression models predicting acute urinary retention, overall early and late complications rates in patients with prostate volume $<100 \mathrm{cc}$ vs. $\geq 100 \mathrm{cc}$ (reference: prostate volume $<100 \mathrm{cc}$ ). All the models were adjusted for age, baseline PSA, BPH\LUTS therapy, antiplatelet\anticoagulant therapy, surgery type and history of catheter indwelling prior surgery.

\begin{tabular}{lcccc}
\hline & \multicolumn{2}{c}{ Univariable } & \multicolumn{2}{c}{ Multivariable } \\
& $\begin{array}{c}\text { Odds Ratio } \\
(95 \% \mathrm{Cl})\end{array}$ & p-value & $\begin{array}{c}\text { Odds Ratio } \\
(95 \% \mathrm{Cl})\end{array}$ & $p$-value \\
\hline $\begin{array}{l}\text { Acute urinary } \\
\text { retention }\end{array}$ & $0.5(0.2-1.3)$ & 0.170 & $0.5(0.2-1.4)$ & 0.217 \\
$\begin{array}{l}\text { Overall early } \\
\text { complications }\end{array}$ & $1.6(1.1-2.4)$ & 0.017 & $1.8(1.2-2.9)$ & 0.009 \\
Overall late & $1.8(1.1-2.9)$ & 0.023 & $2.2(1.3-3.9)$ & 0.004 \\
complications & & & & \\
\hline
\end{tabular}


Table 5 - Median values (interquartile range) of PSA ( $\mathrm{ng} \backslash \mathrm{mL})$, Qmax $(\mathrm{mL} \backslash \mathrm{s})$, IPSS stratified according to the prostate volume with the $\mathrm{p}$-values derived from ranked based model for differences between the prostate volume, follow-up time points and interaction prostate volume and follow-up time.

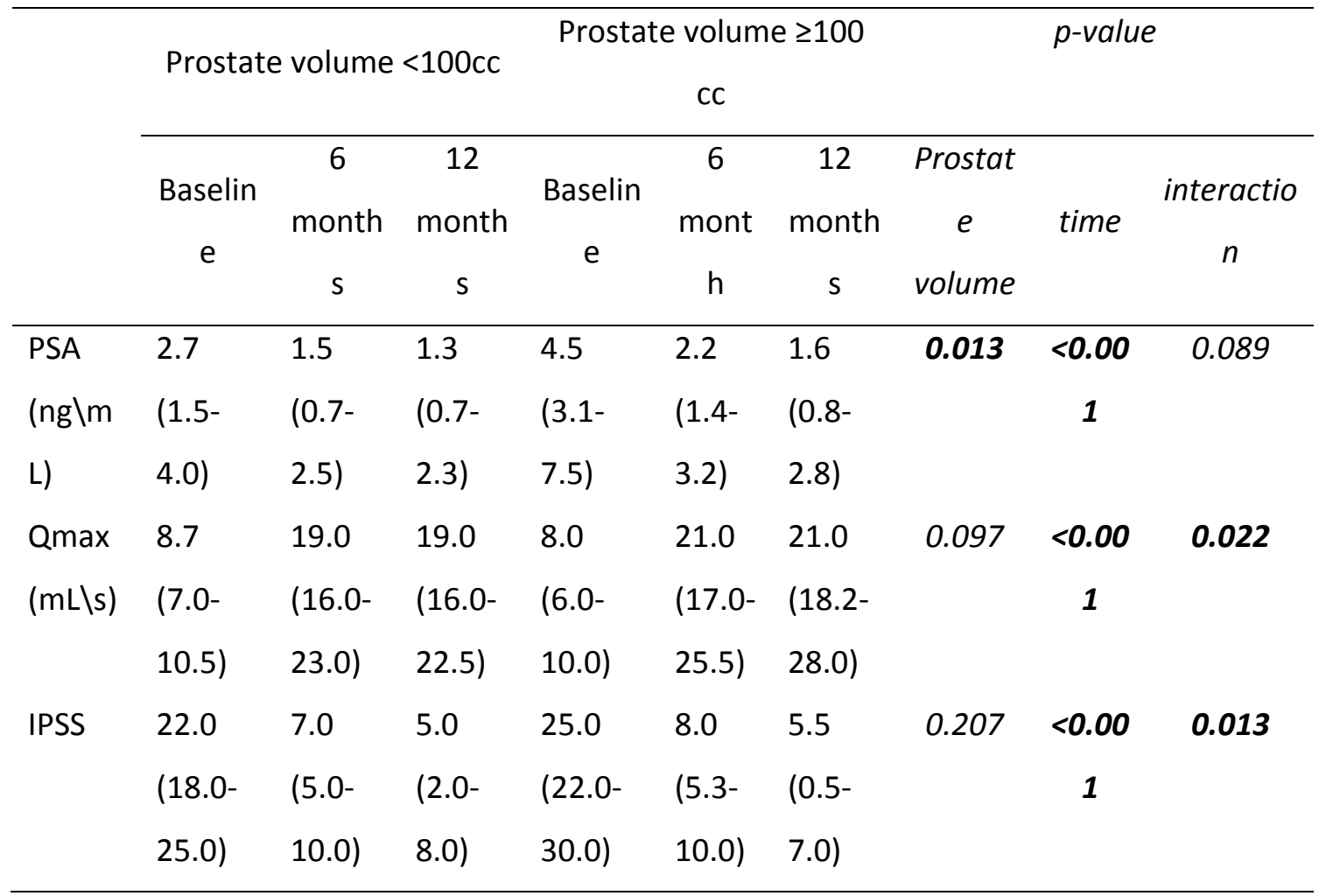


VHP= Very High Power

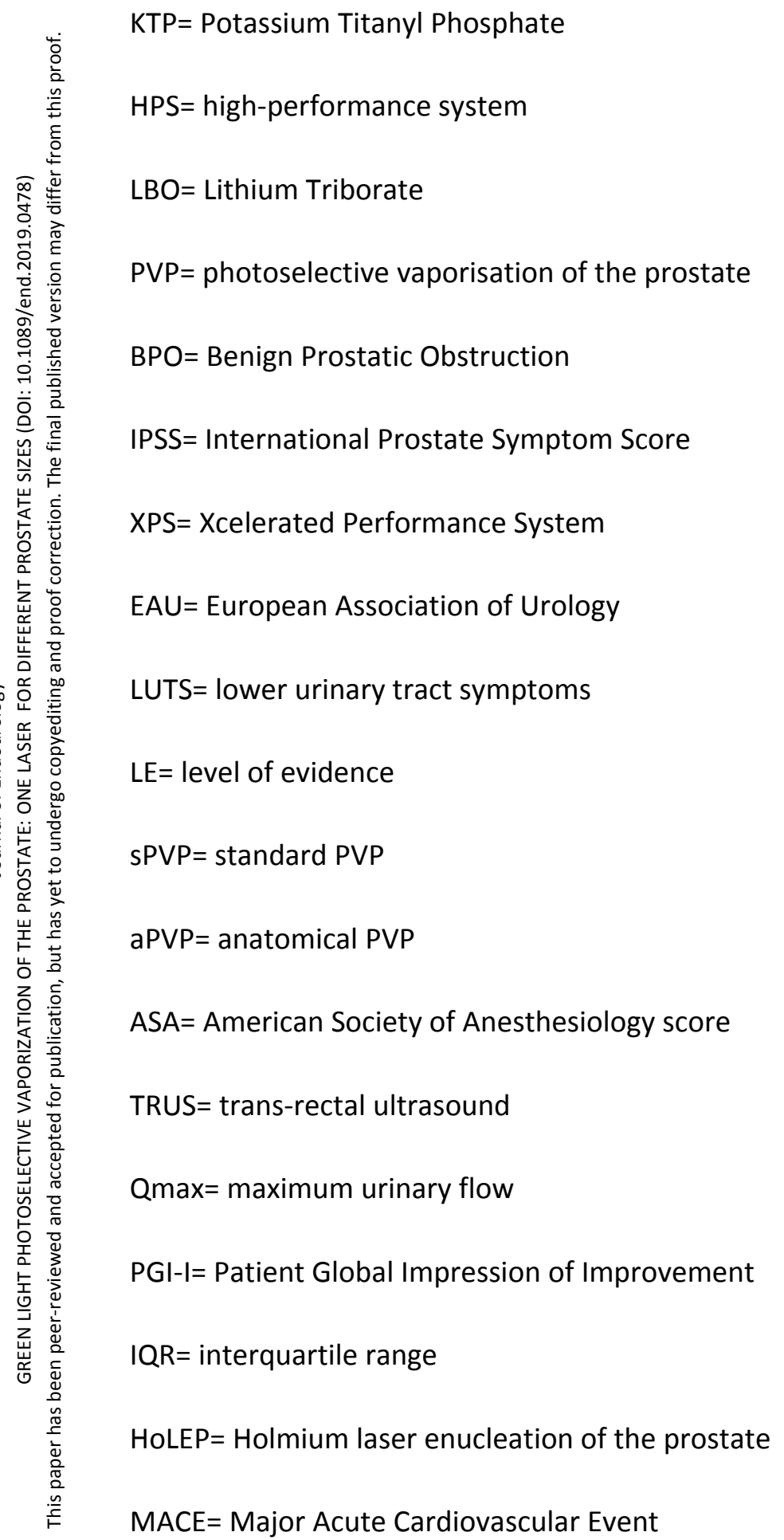

